\title{
Our Existence through Thoughts and Viceversa
}

\author{
Arieșan Ramona Nicoleta ${ }^{1 *}$, Prof. Dr. Veress $\mathrm{Carol}^{2}$ \\ ${ }^{1}$ Phd student, Faculty of History and Philosophy, "Babeş-Bolyai” University, Cluj-Napoca \\ ${ }^{2}$ Coordinating Professor, Faculty of History and Philosophy, "Babes-Bolyai" University, Cluj-Napoca
}

\begin{abstract}
DOI: $\underline{10.36348 / \mathrm{sb} .2020 . \mathrm{v} 06 \mathrm{i} 02.001}$
| Received: 01.02.2020 | Accepted: 08.02.2020 | Published: 15.02.2020
\end{abstract}

*Corresponding author: Ariesan Ramona Nicoleta

\section{Abstract}

The purpose of this paper is to show how our lives are shaped by our thoughts. It might seem like an easy task because we all have different thoughts and we all think that we know how to handle them but I believe the reality is a little bit different. Indeed, we have the ability to think for ourselves, to distinguish between what we feel like is wrong or right but at the same time we often end up in a situation where we are faced with other thoughts. And we do not always know how to cope with them. Also, sometimes we might have deeper thoughts opposite thoughts about a specific subject, a feeling or a person and we feel like we are overwhelmed. It is not something strange. I believe it is part of what makes us human beings. In order to perceive our lives we need to be able to understand how we think so we can shape our existence how we like it not how someone else tells us to do.

Keywords: Thoughts, existence, life, human being, understanding.

Copyright @ 2020: This is an open-access article distributed under the terms of the Creative Commons Attribution license which permits unrestricted use, distribution, and reproduction in any medium for non-commercial use (NonCommercial, or CC-BY-NC) provided the original author and source are credited.

\section{WHAT IS OUR EXISTENCE?}

It is believed that people have always wondered why we are who we are, why we are the way that we are, why we think the way that we think and how can we come to an understanding of our situation. Everything has a beginning and an ending. Even life in general. So, I started to wonder just how exactly our thoughts started to form themselves, to exist and slowly but steadily gain such momentum and such force in our lives.

The capacity for rational comprehension is a fundamental feature of our everyday existence. For example, we recognize that physical objects form phenomenal wholes even if all the parts which go to make up such wholes are not immediately accessible to the senses. In our theoretical or practical projects, we can calculate or comprehend even the fastest and most powerful items in terms of rational concepts $\left[{ }^{1}\right]$.

We are the core of our own existence. It is not the fact that we belong here but the fact that we gain the right to do so. Our existence is based on our will, on our

\footnotetext{
${ }^{1}$ Paul Crowther, The Kantian Sublime.From Morality to Art, Clarendon Press, Oxford, 1989, p.166
}

values, morals and thoughts. What keeps us emerged in this environment is how we can cope with everything that is being thrown at us. We are human beings for a reason. We think, we calculate, we evaluate everything. Sometimes, what may seem as a simple action takes years in order for us to achieve that level of easiness.

We may not always be right or have the best ideas but we know that no matter what we our best and we try to improve every single time however we can. Sometimes, being a person is a difficult task but I do believe that at the end of the day it is all worth it. When we know that we have reached the level that we were striving for, we know that we have accomplished something that will just motivate us to try and go even further.

At the same time, I think that indeed, not every thought that we have, not every action that we make has a good aspect in it but it is still our decision, our vision and of course it is consisted of our thoughts. Also, going along with the general perception, I too believe that our brains are the most powerful tool that we have and can use. Everything started with the human being, from ancient times, has continued with human beings and will keep on going for as long as we exist. 
For most parts of our lives, we reach for philosophers and their knowledge, sometimes without knowing exactly why or without realizing. What I think about this aspect is the fact that we need something to hang on to when there is no one around us, or when no one believes in us. And we are going towards them and towards what they thought at a particular time and place only to realize that we are not alone and that someone has not just thought about the same things as us, even better. We realize that someone has felt like we are feeling and that they have also expressed everything so that others can comprehend their own thoughts.

To recover this primordial experience we must understand spatiality and temporality as a unified fundamental horizon of human existence. This means that our sense of spatial presence and the present moment must first be explicitly informed by a sense of presences and presents which have passed beyond our immediate grasp or recall, and by an anticipation of the unknown number of future presences and presents still to be experienced[2].

Just like I have mentioned above, sometimes we go back to what others that have lived before us realized, experienced and transpose into words. But maybe this is not enough. Maybe we need more in order for us to realize what we have, who we are and we can become. It is strange how sometimes you find neither help in people whom you have never met nor will ever, yet you fill like there is a strong bond and an even stronger intellectual connection. Going back and finding yourself just might give you the strength that you need in order to move forward. This life is filled with unexpected things but at least we know something for sure. There is always a future, no matter what. And I say this because even if we have no idea what is in front of us we know that we are heading towards something. Maybe we cannot explain it or give it a precise shape but we know that there is something. A future.

And we also know that we have a present in which we are living. Now this is another very important aspect, I believe, because as I see it our present is the core of our thoughts. This is the way that I perceive our present because it is the ground that allows us to build our thoughts, it is what keeps them alive and also enables both us and our thoughts to go beyond what we know and sometimes even take a leap into the unknown.

Emergence is generally understood to be a process that leads to the appearance of structure not directly described by the defining constraints and instantaneous forces that control a system. Over time "something new" appears at scales not directly specified by the equations of motion. An emergent

${ }^{2}$ Ibidem, pp.168-169 feature also cannot be explicitly represented in the initial and boundary conditions. In short, a feature emerges when the underlying system puts some effort into its creation [3].

This is what happens with us, with our existence and our thoughts. Everything has to emerge from somewhere and without an idea of a destination, not a particular place but rather a direction, we cannot fully represent just who we are. For most human beings the most difficult question is "what do you want to be when you grow up". I've come to the conclusion that this is such a difficult question because it makes us realize that we need a direction. Without it we would be stuck in the same place, without having the slightest idea about where we are heading towards, how we can reach it or we could end up going in the exact opposite direction but not realizing it.

When we are faced with a decision making moment, we thrive to be better. That can be easy, we just say a few words, look a certain way and everything will be alright. But life happens. And we have to put into action what we expressed with words. That is the difficult task. Usually, we think before we speak. We are thinkers. We are philosophers. But things do not always go as planned. That is why we rely on others when things get tough. And the trust that emerges from them towards us is what keeps us going. It is easy to go back and find help into what people that came before us had to say, in how they portrayed what they experienced. It is easy to find that kind of information. The difficult aspect here is how to extract the right knowledge from it, how to process everything, how to wrap our thoughts around it and how to transpose it for others to come.

\section{[...] Although much of the philosophical literature} on emergence may leave the impression that the issue is primarily about esoteric phenomena such as human consciousness, debates about reduction and emergence occur in a wide variety of more basic areas of science. When considering whether emergent phenomena exist, it is important to note that some of the best-understood candidates for emergence occur within physics, chemistry, biology, various social sciences, and complexity theory[4].

It might seem crazy how life works. It might seem crazy how everything is happening around us. But everything has an explanation and it has all emerged from somewhere. On a philosophical level we could say that it al started with our thoughts and trying to put

\footnotetext{
3 Mark A. Bedau, Paul Humphreys, Emergence: Contemporary Readings in Philosophy and Science, Massachusetts Institute of Technology, London, 2008, p. 269

${ }^{4}$ Ibidem, p.338
} 
things into perspective it kind of did. If it wasn't for the fact that we always wonder where everything is coming from we might not have had a strong enough reason to analyze life, to analyze our minds and our motives. Also, giving our need for knowledge as an excuse for our desires to comprehend things might have just given us a gate towards better understanding of what this life means, of what we need to do and on how others did what they did and why they did it. Is a complex maze, this mind that we hold, but the journey towards understanding it is even more complex and at the same time more interesting than we could imagine.

Another strange aspect, at a first glance, is how we can find help within our surroundings. Other organisms may not appeal to us but if we take a closer look, they do have similarities and by studying them we can learn a lot more than just by studying other human beings. Something that has a different core than we do can give us answers that otherwise would have been out of our reach. For examples we can learn from animals and plants how they adapt into different scenarios, to different weathers and how they have dealt with all the obstacles that they have faced. But maybe one of the most important things that we can learn from what is surrounding us is the fact that we all share a bond, that we are connected by feelings, even though we may not always seem like we are or behave like that.

Although it was generally accepted that particular patterns of feeling help to define specific forms of the good life, the exact nature of these patterns was a much more contentious issue, and authority to pronounce on it was shared between a number of traditions, each with its own internal disputes and complexities. From classical times, medical specialists had been regarded as experts on the causes and control of the affects, and they retained this role throughout the early modern era [5].

We all have different shapes, different sizes, different aspects, different values, different morals and different thoughts. We are the same from a variety of aspects but at the same time we are so different from one-another that it is almost incredible. We tend to search in others what is it that we like in ourselves and we also tend to become frustrated when that does not happen. It is a situation that occurs quite often but unfortunately or maybe fortunately we cannot do anything about it.

Everything in life can have a bad aspect or a good one, depending on how you look at it. For some, not finding what they are exactly looking for in others could mean the end of the world. Could mean that they

\footnotetext{
${ }^{5}$ Donald Rutherford, The Cambridge Companion To Early Modern Philosophy, Cambridge University Press, Cambridge, 2006, p.199
}

will not be able to find that particular aspect anywhere which could translate into them not being able to find all the answers that they were looking for. But it could also mean that this lack of knowledge will lead them towards a negative extreme point in which they would end up not wanting to do anything anymore, not wanting to search for the answers, not wanting to fight for what was important to them at some point.

On the other hand, if you know what to do with the information you can change the entire situation around. In this case, if you do not find exactly what it is that you are looking for in someone else you could go one of two ways. You could change what you are looking for, try to understand why you didn't find the first aspect, analyze the situation and search for something else, something that resembles what you were searching in the first place but also has a more objective approach so you do not have to feel strange because you could not find it. Or, you could try to look in others for what is of interest for you. At first this might seem like a more radical approach because it means that you need to abandon the first person in order to find exactly what you are looking for and this might make you feel overwhelmed. But you should not give up because if something is really important to you it means that you are willing to give everything that you have just to achieve your goal. Even if that means giving up UN something that you thought was for and start all over again.

The idea that virtue depends on selfknowledge, which in turn includes an understanding of one's passions, had an ancient lineage. But the precise nature of the knowledge involved was hotly disputed, as was the kind of life it vindicated. One dimension of this disagreement, which became increasingly prominent in the course of the seventeenth century, concerned the relationship between ethical questions about virtue and natural philosophy[6].

The hardest road in life is the one towards you. It has the most difficult obstacles, it makes you take the hardest paths towards you destination, it makes you realize the world in which we are living, it makes you aware of who is there for you, for real, and who just uses words to keep you around. Basically, it makes you question everything that you know, it makes you question yourself and in the end, when you finally realize everything, it makes you thankful not only for what you have or what you have learned, but also for the fact that you did not give up and you pushed through despite everything. Being a human being is not an easy task. Becoming an even better human being...now this is something worth trying. We are all born somewhere and we are taught that we belong there no matter what. That even if we end up on the opposite

\footnotetext{
${ }^{6}$ Ibidem
} 
part of the globe a part of us will always remain there. To put things into perspective, as far as I am concerned, this means that no matter what we we will always have a bond with the place where we were born.

I believe that this applies only to some people, because despite the fact that we are being born somewhere we do not necessarily connect with that place, with what it stands for or with the values that it promotes. Generally, places do not change. What changes are the people who live there, their way of thinking and their way of comprehending this life? As they learn more about what is going on, as they learn more about what makes or breaks someone, as they learn more how to cope with all that is changing they reach different conclusions. From the moment they reach their first conclusion that is different from what they were thought everything changes because they no longer see the world as they were told to, but they start to see it as they see fit.

\section{How to think}

Something analogous is true of freedom of movement, which is tempered by emotion and habit, and freedom of consent, which in the very words 'freedom of consent' is revealed the paradoxical nature of this formula: consenting is the voluntary act of surrendering freedom. All of these paradoxical formulations describe modes of specifically human freedom, and human freedom is limited by the negative concepts - need, emotion or habit and necessity - which determine it by the possibility of the will's rejecting them [...][7].

Thinking makes us human. It enables us to look at things in a different way, it provides us the tool that we need in order to perform different activities. But it means so much more. We thrive to become better to overcome any obstacles to be aware of what is happening and, in most cases, to be able to help those who need our help. Our thoughts are our guidance through life. At least this is my point of view. Not only they give us the power to analyze, to comprehend and to transpose what is going on around us and inside of us at the same time but they also give us the ability to be someone else. I strongly believe that we are more than what meets the eye. We look at ourselves in the mirror and see and image. We look at someone else and see another image. But we do not see what others do. We can only imagine. And we do that with our mind and with our thoughts. Sometimes is for the better. Others not so much. But in the end, hopefully, we realize that what is important is not what someone see when they look at us but what we see.

Just we like for something in particular in others they do the same and maybe they end up finding

\footnotetext{
${ }^{7}$ Karl Simms, Paul Ricoeur, Routledge, London, 2003, p.14
}

what they have been looking for in us. But it is not because they saw it like that or because they thought they did. I believe it is because we were the way that we are, and the reason behind that is because we know us, we get to know us and to portray it just like it is.

So, in order to comprehend my life as a whole, I must adopt a perspective or point of view: I view my birth not from a past perception of a 'here', but by in some sense stepping outside myself, and seeing myself as others would see me. In doing this I am already going some way towards 'transgressing' the finitude of my life, and I perform a similar transgression in order to realize that my life is finite, and then to discourse upon that finitude [8].

We need to think about ourselves as a whole and see every single part that makes us who we are. Putting the pieces together, starting from our birth up until this moment, making and describing our structure are a difficult task. We need to start thinking about a lot of aspects, about a lot of ifs, about so many scenarios when we did something and things went away and what would have happened if we had not made that decision. We need to find the reasons behind our actions because otherwise they will catch up to us and we will not be able to do anything about it.

The common conviction today is that we can give natural scientific explanations for all living functions, and that we can also account for the origin of life by strictly physicalist non-teleological concepts. Moreover, it is argued that the social norms of behavior and linguistic meanings can be naturalized. In contrast, the subjective or phenomenal aspect of consciousness seems to fall outside the natural scientific framework of explanation [9].

It is indeed very hard to put into words every action and every thought. Because we cannot always explain just why we fell a certain way. But even though we cannot express everything how we want to, we can try and find ways to do it so that at least the main focus is explained. Maybe we do not end up with the result that others were expecting but we do end up with something that satisfies our minds because we know that we did our best.

We can accept the core of our subjectivity as a given, go on living and thus repeat and reinterpret that which has already been created - perhaps, at best, examining its effects on those levels of mentality and life that are within the reach of our powers of

\footnotetext{
${ }^{8}$ Ibidem, p.17

${ }^{9}$ Sara Heinämaa, Vili Lähteenmäki, Pauliina Remes, CONSCIOUSNESS. From Perception to Reflection in the History of Philosophy, Springer, The Netherlands, 2007, p.15
} 
reflection; alternatively, we can engage in this task more actively, by construing, constructing and creating ourselves [10].

In the end, the most important aspect is our understanding for who we are. People need to figure out who they are. Sometimes this happens in the early stages of our journey called life but it is not always the case. Yet, those who do not give up are the real deal and they are who I am looking at as role models. We start with a specific mindset which can change along the way. For some it does and for others it does not. But this is not the main element. Because we do not function the same way as others and certainly we do not think as others. Still...we have something in common. We all think.

\section{CONCLUSION}

Everything starts with the fact that we think in order to exist. We need that; we embrace it and make it ours. We shape who we are based on what we think, on what we desire, on what we are following. We have examples and we can become an example for someone else. We never know. We got through life without truly realizing the impact that we make but at the same time the impact that it has on us. Usually we start low and we build our way to the top. A difficult journey if you ask me. Sometimes we stop somewhere along the middle. Still a difficult journey because it implies a very hard decision: to stop. To have answer in case we start wondering why we stopped somewhere along the middle and not go all the way to the top. Realizing the true potential, realizing the fact that it would have been impossible to reach the top without losing ourselves or without becoming something we are not.

Getting to know you for the real you, getting to understand your way of thinking, of seeing and comprehending life, your way of judging what is going on (because we do it), understanding what got you to where you are...I believe that this is what gives someone the ability to be who they truly are. Our existence is through our thoughts but our thoughts are based on our existence. They are a perfect match and no one can deny that. We are strong because we believe that we are and we are brave in order to prove that.

It does not take much but it does take a lot of time. First and foremost we must be aware of our thoughts, understand them, see where they are coming from and use them to our advantage. At the end of the day they are what we are left with and we need to be able to live with them. They are who we are. Based on life, on experiences, on what we have learned from those who came before us and felt us their knowledge and maybe it is up to us to express how we think because we never know just who might end up needing our thoughts.

\section{REFERENCES}

1. Heinämaa, S., Lähteenmäki, V., \& Remes, P. (Eds.). (2007). Consciousness: From perception to reflection in the history of philosophy (Vol. 4). Springer Science \& Business Media.

2. Simms, K. (2003). Paul Ricoeur. Routledge.

3. Rutherford, D. (2006). The Cambridge companion to early modern philosophy.

4. Bedau, Mark, A. (2008). Paul Humphreys, Emergence: Contemporary Readings in Philosophy and Science, Massachusetts Institute of Technology, London.

5. Crowther, P. (1989). The Kantian Sublime. From Morality to Art, Clarendon Press, Oxford.

${ }^{10}$ Ibidem, pp.19-20 